\title{
A pandemia de COVID-19 para além das Ciências da Saúde: reflexões sobre sua determinação social
}

\author{
The COVID-19 pandemic beyond Health Sciences: reflections on \\ its social determination
}

Diego de Oliveira Souza (https://orcid.org/0000-0002-1103-5474) ${ }^{1}$

${ }^{1}$ Universidade Federal de Alagoas. Av. Manoel Severino Barbosa, Bom Sucesso. 57309-005 Arapiraca AL Brasil. enf_ufal_diego@ hotmail.com

\begin{abstract}
This paper aims to perform a theoretical reflection on the historical-social foundations of the COVID-19 pandemic. The "capital worldization", "capital-imperialism", "spacetime compression", and "structural crisis of capital" categories are conjured from the historical materialistic-theoretical matrix, outlining a course that transcends the limits of Health Sciences to understand global health, of which the COVID-19 pandemic is an expression. We then return to the field of health, when the category of "social determination of health" allows elucidating the bases of the pandemic studied. We show that, other elements typical of the current phase of contemporary capitalism have become universal besides the SARS-CoV-2 characteristics or the dynamics of the rapid movement of people and objects around the world, unifying the health social determination process.
\end{abstract}

Key words Capitalism, Coronavirus, Healthdisease process, Global health, Public health
Resumo Este artigo possui o objetivo de realizar uma reflexão teórica sobre os fundamentos histórico-sociais da pandemia de COVID-19. A partir da matriz teórica materialista histórica, evoca-se as categorias da "mundialização do capital", "capital-imperialismo", "compressão espaço-tempo" $e$ "crise estrutural do capital" traçando um percurso que ultrapassa os limites das Ciências da Saúde a fim de entender a saúde global, da qual a pandemia de COVID-19 é expressão. Posteriormente, faz-se o retorno ao campo da saúde, quando a categoria da "determinação social da saúde" permite elucidar as bases da pandemia estudada. Demonstra-se que, para além das características próprias do SARS-CoV-2 ou da dinâmica de rápido trânsito de pessoas e objetos pelo mundo, há outros elementos típicos da atual fase do capitalismo contemporâneo que se tornaram universais, unificando o processo de determinação social da saúde.

Palavras-chave Capitalismo, Coronavírus, Processo saúde-doença, Saúde global, Saúde pública 


\section{Algumas questões introdutórias}

Foi a pandemia de COVID-19 que provocou uma desordem econômico-social ou o caos social intrínseco ao sistema econômico vigente que estabeleceu as bases sociais para a pandemia? Para além do novo coronavírus, qual a trama causal da pandemia? Este ensaio é apresentado com o objetivo de trazer uma contribuição teórico-reflexiva desenvolvida a partir de tais questionamentos, buscando ir além da discussão dos âmbitos da infectologia e epidemiologia, embora deles não prescindindo.

A COVID-19 trouxe impacto nas vidas dos indivíduos em nível global, chamando a atenção pelo alcance que teve e pela velocidade com a qual se disseminou. Alguns dados históricos, embora ainda muito recentes para uma análise rigorosa, revelam essa dinâmica espaço-temporal da doença. A Organização Mundial de Saúde $(\mathrm{OMS})^{1}$ recebeu a notificação, em 31 de dezembro de 2019, de casos de pneumonia na cidade de Wuhan, na China, com suspeita de serem provocados por uma nova cepa de Coronavírus. Uma semana depois, as autoridades chinesas confirmaram se tratar de um novo tipo do vírus, recebendo o nome de SARS-CoV-2. Ainda no mesmo mês (30 de janeiro), a OMS emite alerta de emergência de Saúde Pública de importância internacional devido à velocidade com a qual se espalhava entre os continentes e, em 11 de março, a situação é classificada, oficialmente, como uma pandemia ${ }^{1}$, embora já se apresentasse em quase todos os continentes em fevereiro.

Historicamente, a humanidade experimentou outras pandemias, algumas com ciclos repetidos por séculos, como a varíola e o sarampo, ou por décadas, como as de cólera. Ainda podem ser citadas as pandemias de gripe por $\mathrm{H} 1 \mathrm{~N} 1$ em 1918, por H2N2 em 1957-58, por H3N3 em 1968-69 e por H5N1 nos anos 2000, conhecidas, respectivamente, como "gripe espanhola", "gripe asiática", "gripe de Hong-Kong” e "gripe aviária”, em que pese tais denominações que carregam estigmas que devem ser evitados ${ }^{2}$.

Os números relacionados à pandemia de COVID-19 são, cada vez mais, alarmantes, com dimensões globais. Em 17 de abril de 2020 já eram 2.074.529 casos no mundo, 1.050.871 na Europa, 743.607 nas Américas (sendo 632.781 só nos Estados Unidos da América - E.U.A.), 127.595 nos países do Pacífico Ocidental, 115.824 na região do Mediterrâneo Oriental, 23.560 no sudeste asiático e 12.360 na África. No Brasil, na mesma data, eram 28.320 casos, em que pese haver sub- notificação, assim como em todo mundo, pela não testagem da totalidade dos sintomáticos ${ }^{3}$.

Esses números servem para a caracterização de apenas uma face, embora importante, do problema em questão, ora objeto da reflexão que desenvolvemos na direção de contribuir para o entendimento dos seus fundamentos históricosociais. Isto é, para além dos números, buscamos esclarecer a natureza e a dinâmica do processo de determinação social da saúde em nível global, ainda que em termos muito genéricos e preliminares. O caso da pandemia da COVID-19 comparece enquanto expressão de um movimento maior, a partir do qual apreendemos particularidades que permitem, sob o prisma do materialismo histórico, tecer correlações com a universalidade social.

Além desta seção introdutória, apresentamos outras três. Na primeira, a discussão faz um movimento de ida, para fora das Ciências da Saúde, na busca pelos fundamentos da saúde global, quando dialogamos com proposições de Chenais $^{4}$, Fontes ${ }^{5}$, Harvey ${ }^{6}$ e Mészáros ${ }^{7}$. Na segunda seção, a categoria "determinação social da saúde", com autores como Laurell ${ }^{8}$ e Breilh", é o ponto nodal para fazermos o caminho de volta, trazendo as contribuições de tal viagem a fim de analisar a pandemia da COVID-19. Na última seção, fazemos apontamentos para fechar o raciocínio deste ensaio, com reflexões para serem pensadas agora e aprofundadas ulteriormente.

\section{Algumas considerações fundamentais}

O capitalismo contemporâneo é marcado pela articulação das nações no interior de um "organismo" que funciona mundialmente. Tratase de uma dinâmica (a priori, econômica) de eliminação das fronteiras para a expansão do capital, descrita por Chesnais ${ }^{4}$ como um fenômeno de "mundialização". Consoante Fontes ${ }^{5}$, a formulação de Chesnais é mais elaborada do que aquelas que fundamentam a análise do atual momento do capitalismo a partir da ideia da neoliberalização enquanto uma fase de ruptura ante o Welfare State vivido em algumas nações, o que a autora classifica como uma crítica pontual à fase e, não, ao sistema. A mundialização seria, ainda, um termo mais adequado do que "globalização" e a pretensa neutralidade que, segundo seus propagandistas, ela carrega, enquanto um processo conduzido pela integração tecnológica, informacional e um suposto saudável intercâmbio comercial. Apesar disso, a autora prefere denominar essa fase como sendo o "capital-imperalismo" em vez de "mun- 
dialização do capital", dando ênfase às sucessivas expropriações que as nações dependentes sofrem por parte das nações imperialistas.

Mesmo com algumas diferenças, Chesnais ${ }^{4} \mathrm{e}$ Fontes ${ }^{5}$ estão chamando a atenção para uma conformação espaço-temporal contemporânea que é fruto da dinâmica expansiva do capital ante sua perene luta contra a queda tendencial da taxa de lucros, apenas amenizada pela aceleração da rotação do capital, bem como pela hierarquização entre as nações nesse sistema mundial. Por conseguinte, foi preciso reconfigurar as fronteiras geopolíticas, eliminado os obstáculos à intensa circulação do capital, em especial o financeiro, dada sua natureza especulativa que consegue, ainda que ilusoriamente, gerar a sensação de administração da inexorável ameaça de pletora.

Essa nova dinâmica se reproduz em (e com) todas as formas as quais o capital possa assumir, basta observar que, por exemplo, cada vez mais, o capital industrial se distribui pelo mundo, tendo em vista as empresas transnacionais. Porém, seja para qualquer forma que o capital possa assumir, o que se sobressai é, primeiro, a rápida metamorfose que ele sofre e, segundo, que esse ritmo alucinante é dado na esfera financeira. Sobre isso, Chesnais ${ }^{4}$ explica que "para tudo que pertence à esfera visível das mercadorias, são os grupos industriais transnacionais (os FMN) que têm a condição de assentar a dominação política e social do capitalismo. Porém, não são eles que comandam o movimento do conjunto da acumulação hoje. Ao término de uma evolução de vinte anos, são as instituições constitutivas de um capital financeiro possuindo fortes características rentáveis que determinam, por intermédio de operações que se efetuam nos mercados financeiros, tanto a repartição da receita quanto o ritmo do investimento ou o nível e as formas do emprego assalariado".

Essas instituições são baluartes da dinâmica contemporânea, porquanto a efemeridade das transações que cultivam dê vazão ao tipo de relações exigidas pela reprodução do capital em escala internacional. Elas dão a tônica da transformação do espaço e do tempo no mundo, criando uma rede de interconexões amplas, embora desiguais. Harvey ${ }^{6}$ foi assertivo sobre esse debate quando analisou o que ele chama de "compressão espaço-tempo". O autor demonstra como essa articulação mundial demanda um ritmo compatível ao novo padrão de acumulação pós-obsolescência do taylorismo/fordismo, caracterizado agora pela flexibilidade. Com efeito, "a aceleração do tempo de giro na produção envolve acelera- ções paralelas na troca e no consumo. Sistemas aperfeiçoados de comunicação e de fluxos de informações, associados com racionalizações nas técnicas e distribuição (empacotamento, controle de estoques, conteinirização, retorno do mercado etc.) possibilitaram a circulação de mercadorias no mercado a uma velocidade maior. [...] Serviços e mercados financeiros (auxiliados pelo comércio computadorizado) também forma acelerados, de modo a fazer, como diz o ditado, 'vinte e quatro horas ser um tempo bem longo' nos mercados globais de ações"6.

Diante disso, é com a dinâmica da acumulação flexível que se instaura uma nova perspectiva de tempo para o capital. Fontes ${ }^{10}$ atualiza o debate ao mencionar o papel que cumpre hoje a indústria $4.0 \mathrm{com}$ os processos de $e$-comerce, a uberização do trabalho, a explosão de startups e a tendência, cada vez maior, de relações instantâneas por via digital. Conforme Harvey ${ }^{6}$, trata-se de um panorama desenhado desde os primeiros estágios da implementação da acumulação flexível e a sua tendência de derruir o espaço pela nova perspectiva de tempo. Assim, "com a redução das barreiras espaciais, aumenta muito mais a nossa sensibilidade ao que os espaços do mundo contêm. A acumulação flexível explora tipicamente uma ampla gama de circunstâncias geográficas aparentemente contingentes, reconstituindo-as como elementos internos estruturados de sua própria lógica abrangente"'.

Essa transformação espacial não elimina a particularidade daquilo que Harvey ${ }^{6}$ chamou de "lugar", delimitada por costumes e tradições conservados, embora refuncionalizados, uma vez que as peculiaridades assumem signos de valor no mercado mundial. Trata-se de uma antítese entre espaço e lugar, porquanto aquele se torna universal, representado pela fluidez de suas relações econômica e sociais em geral, isto é, criando um sistema universal no qual conservar lugares pode gerar novas formas de expropriação. Esse movimento dialético de transformar-conservar apenas se justifica na superfície do processo, pois, de fato, está subordinado a uma transformação genérica do ritmo de vida, a reboque da dinâmica econômica, exercendo prioridade sobre as particularidades locais. Uma série de comportamentos, padrões de alimentação e moda, estilos artísticos e alternativas de cultura aparecem e somem a todo momento, absorvendo e repelindo tradições, criando ou resgatando produtos e serviços, em uma espiral de fugacidade que retroalimenta as necessidades de consumo e, portanto, circulação, distribuição e produção. 
Essa expansão desesperada exprime a dinâmica de um sistema estruturalmente em crise, que chegando aos seus limites, parece não mais caber nas fronteiras mundiais, a não ser pela fantasia de novas fronteiras criadas digitalmente na dinâmica financeira. A nosso ver, Mészáros ${ }^{7}$ não deixa dúvida sobre a raiz mais profunda desse movimento contemporâneo, uma vez que localiza a reconfiguração produtiva, na sua flexibilidade e votabilidade, no bojo das respostas do capital à sua própria crise, agora com caráter diverso dos ciclos críticos anteriores, sendo, mesmo, estrutural, global e rastejante. Apenas uma crise dessas proporções (que se arrasta da década de 1970 até hoje, embora com ciclos internos de deslocamentos e disfarces) poderia gerar respostas de tal magnitude, em uma tentativa de o capital remediar o irremediável.

Para Mészáros ${ }^{7}$, as contradições do capital se tornam mais claras do que nunca, sobretudo pelos seus defeitos estruturais. Aqui, convém mencionar a contradição que o autor aponta na relação entre produção e circulação, reverberando noutro paradoxo, constituído do conflito entre a dinâmica universalizante do capital e os interesses das burguesias nos limites nacionais.

Isso porque cada nação, internamente, vê seus interesses particulares ameaçados por uma demanda vital ao sistema como um todo, qual seja: eliminar as fronteiras para o capital, o que pode levar a desvantagens ao mercado interno. A saída encontrada no interior do sistema, segundo o autor, é a de constituir uma hierarquização entre as nações, com orientações econômicas e políticas que são diferentes a depender da posição da nação nessa hierarquia e que, assim, determinarão quais nações terão seus interesses internos mais ou menos atendidos. Entretanto, o caráter estrutural da crise coloca esse sistema sob bases tão frágeis, que o menor abalo de economias nacionais é capaz de fazer transparecer o caráter estrutural, por vezes latente, da crise. Portanto, esse movimento de articulação (hierarquizada) do mundo é a resposta do capital ao seu período estruturalmente mais crítico, porque crônico, o que gera as já citadas consequências no tempo, espaço, cultura etc. Sendo que, deixe-se registrado, tais respostas vêm se revelando tóxicas em vez de remediantes ${ }^{7}$.

Como vimos, alguns autores já se propuseram a explicar essa dinâmica mundial para além de sua aparência, elucidando uma tendência de generalização da forma como nos movimentamos, pensamos, agimos e em qual tempo e com quais objetivos, o que reverbera em todos os complexos sociais, a exemplo dos efeitos incisivos que se percebem hoje na saúde, cuja pandemia da COVID-19 é o exemplo mais eminente.

\section{Algumas considerações sobre a saúde globalizada}

A dinâmica que vimos descrevendo parece ter uma clara ligação com a pandemia da COVID-19, porquanto a nova dinâmica espaçotemporal permitiu que, rapidamente, o vírus se disseminasse. Para chegar a tal conclusão não é necessário nenhuma reflexão teórica mais complexa. Todavia, o que queremos salientar aqui é que: 1) essa dinâmica não representa um mero fenômeno natural, revestido de neutralidade para unificar o mundo e permitir o progresso; 2 ) para além do trânsito de pessoas e objetos de amplo e rápido alcance, há uma unificação do processo de determinação social no mundo.

Sobre a primeira questão, já vimos descrevendo sua origem econômica, quando no último terço do século XX se tornou madura ao ponto de conferir às grandes empresas o caráter de mundiais. Ressaltamos que tal fase foi a convergência de um processo de expansão do capital que se insinuava desde a transição do feudalismo para o capitalismo, especialmente pelas navegações na corrida por conquistas coloniais a partir das quais foi possível impulsionar a acumulação primitiva de capital nas nações de capitalismo clássico. Desde esse período, os efeitos sobre a saúde global são sentidos. Berlinguer ${ }^{11}$ afirma que "a globalização das doenças, ou seja, a difusão dos mesmos quadros mórbidos por todas as partes do mundo começou no ano de 1492, com a descoberta (ou conquista) da América, que assinalou, para povos e doenças, a passagem da separação à comunicação. Antes disso, diferentes condições de ambiente, de nutrição, de organização social e cultural, de presença ou ausência de agentes e de vetores biológicos das doenças transmissíveis haviam criado quadros epidemiológicos muito desiguais, no velho e no novo mundo".

A reprodução da dinâmica universal do capital se particulariza, entre outras mediações, na (e pela) saúde, evidenciando seu caráter social. Como afirma Laurell ${ }^{8}$, isso vale tanto para o nível individual de saúde, quanto para o coletivo e, no caso ora analisado, em termos globais. Aqui convém a ressalva de que reconhecer tal caráter não significa anular as determinações biológicas da saúde, ao contrário disso, significa elevá-la a um novo patamar de existência. Lembremos a reflexão luckacsiana sobre o caráter geral do ser 
social, ao demonstrar que, pela mediação do trabalho, o ser humano é autor e ator de um salto ontológico desde a esfera natural (biológica) de existência a uma nova, de caráter social, afastando-se constantemente daquela condição, mas sem dela prescindir ${ }^{12}$.

A universalidade do ser social se expressa em todos seus complexos parciais, respeitando suas particularidades. No caso da saúde, Souza ${ }^{13}$ enfatiza que "pensar em processo social dessa forma significa, também para o caso da saúde, vislumbrar uma dinâmica articulação entre biológico e social, indivíduo e coletividade, que se expressa de diferentes formas. Esta é a essência do processo saúde-doença, de natureza radicalmente histórica, engendrada a partir das (e nas) relações sociais, e não como uma espécie de núcleo imutável definido aprioristicamente".

Considerar esse princípio teórico é importante para não cair em análises fatalistas, eliminando-lhes o caráter conjuntural ou, o que seria mais grave, a questão da causalidade própria da saúde. Pensemos no caso da COVID-19: ainda que as bases sociais estejam dadas com a mundialização do capital, determinações biológicas específicas precisaram se articular a essas possibilidades objetivas para resultar na pandemia experimentada em 2020. Não é qualquer doença infecciosa que se tornará pandêmica ou que será transmitida tão rapidamente entre os indivíduos. A combinação de fatores como a novidade do agente etiológico, seu potencial de transmissibilidade, o grau de imunização da população, as medidas de profilaxia e tratamento mais ou menos conhecidas, entre outros aspectos compõem esse processo.

$\mathrm{O}$ intenso intercâmbio entre a esfera biológica e a esfera social é fundamento ineliminável do processo saúde-doença, embora se expressando de diferentes maneiras ao longo do tempo e do espaço. Mesmo a epidemiologia tradicional, no seu pragmatismo, foi capaz de captar tais diferenças, quando alguns de seus teóricos defenderam a ideia de transição epidemiológica, basicamente, pelos seguintes motivos: (i) existe um processo longo de mudanças nos padrões de mortalidade e adoecimento, em que as pandemias por doenças infecciosas são gradativamente substituídas pelas doenças degenerativas e agravos produzidos pelo homem; (ii) durante essa transição, as mais profundas mudanças nos padrões de saúde-doença ocorrem nas crianças e nas mulheres jovens; (iii) as mudanças que caracterizam a transição epidemiológica são fortemente associadas às transições demográfica e socioeconômica que constituem o complexo da modernização; e (iv) as variações peculiares no padrão, no ritmo, nos determinantes e nas consequências das mudanças na população diferenciam três modelos básicos de transição epidemiológica, o clássico ou ocidental, o acelerado e o contemporâneo ou prolongado"14.

A ideia de transição epidemiológica, em alguma medida, expressava mudanças temporais na saúde global, mas também exigiu atenção para as diferenças regionais, tanto que, por certo tempo, valeu a assertiva de que em países pobres, como o Brasil, essa transição nunca se completou, sendo classificada como uma transição "polarizada prolongada", sobretudo pela "superposição de etapas - incidência alta e concomitante das doenças de ambas as etapas, pré e pós-transição"14.

Em geral, dava-se mais importância à questão demográfica para explicar a transição ocorrida nos países de capitalismo clássico e só quando se olhava o perfil dos países de capitalismo atrasado é que questões como a pobreza ou a fragilidade do sistema de saúde vinham à tona. Contudo, concordamos com Laurell ${ }^{8}$, quando salienta que a determinação social não se resume à questão demográfica, sendo suas raízes localizadas na estrutura e dinâmica do modo de produção. A clássica análise da autora, na década de 1980, na comparação entre México (de capitalismo dependente), Cuba (com uma tentativa de socialismo) e Estados Unidos das Américas (de capitalismo avançado) revela como as formas de articulação entre as forças produtivas e as relações sociais de produção produzem diferenças nos perfis de saúde.

Essa análise permite perceber que, no caso do México, onde há atraso e dependência nas relações de produção capitalista, predominam taxas significantes de doenças infectocontagiosas, mesmo já conhecidas as formas de evitá-las. Já nos casos estadunidense e cubano, prevalecem patologias como neoplasias malignas, doenças cardiovasculares e crônico-degenerativas em geral. Todavia, os casos estadunidense e cubano guardam importantes diferentes. Nos Estados Unidos, as taxas das doenças crônico-degenerativas eram, à época da análise de Laurell ${ }^{8}$, consideravelmente maiores do que em Cuba. No caso cubano, há necessidade de uma investigação mais rigorosa, mas se presume que (consoante a autora) as estratégias adotadas pelo governo local tiveram êxito no combate às doenças infectocontagiosas, mesmo sem ter o suposto padrão de desenvolvimento urbano capitalista. Assim, o perfil patológico do país acompanhou a tendência global de crescimento das doenças crônico-degenerativas, mas 
sem tanta pujança, tendo em vista as diferenças no estilo de vida ${ }^{8}$.

A partir disso, em que pese as mediações temporais a serem consideradas, pode-se refutar a ideia de que a mudança do perfil epidemiológico se deve, simplesmente, ao envelhecimento populacional, relegando todo um padrão de organização da vida social corolário à compressão espaçotempo e que é hostil à saúde de formas diferentes e mais agressivas. Com isso, chegamos à segunda questão antes mencionada: a unificação do processo de determinação social da saúde. Tal unificação não pode ser entendida como homogeneização, haja vista as diferenças aqui já abordadas nas vias de desenvolvimento capitalista nas várias nações. Em vez disso, queremos apontar o processo de universalização de alguns elementos-chave do capitalismo, amadurecidos ante o fenômeno da mundialização e que, nessa nova dinâmica, consubstanciam uma unidade heterogênea.

Novamente, parte da epidemiologia tradicional consegue perceber essa transformação em nível fenomênico, mas não em suas determinações mais profundas. Ao menos, alguns autores abandonam a ideia de transição epidemiológica completa ou incompleta e passam a visualizar um perfil de saúde globalizado: "uma das principais características da Saúde Global, e que a diferencia das formas tradicionais da saúde internacional, é o reconhecimento dos contextos regionais e locais, das diferenças políticas, econômicas, sociais e culturais entre os países e as internas, em cada um, assim como as consequências e as respostas diferenciadas a eventos globais"15.

Embora esse raciocínio sirva para explicar as transformações mais superficiais, não atinge a correlação do processo expansivo do capital na tentativa de reverter sua queda tendencial na taxa de lucros, com as consequentes financeirização e mundialização. Portanto, as raízes materiais do processo que se popularizou pela pecha de globalização são deixadas de lado. Breilh ${ }^{9}$ faz ressalvas sobre essa forma de avaliação da saúde por parte da epidemiologia tradicional, defendendo outro caminho metodológico, que ele denominou de epidemiología de la determinación de la salud. Para o autor “[...] la epidemiología para tornarse emancipadora, a la par que requirió una revolución metodológica, debió adquirir una identidad contestaría, que sólo podía ser legítima adhiriendo a la visión profunda de un câmbio civilizatorio frente a un sistema social inviable e incompatible con la vida y la salud".

$\mathrm{Na}$ esteira das teorias mais críticas da Saúde Coletiva, portanto, fica clarividente que uma saúde globalizada é resultado de uma dinâmica capitalista também globalizada. Consoante à epidemiologia tradicional, costuma-se alertar para a importância das variáveis espaço, tempo e pessoa; em uma perspectiva crítica também não se pode ignorá-las, mas se deve avançar para o entendimento do que a elas subjaz. Nesse ínterim, revela-se a compressão espaço-tempo, assim como a formação de uma cidadania cosmopoli$\mathrm{ta}^{5}$, enquanto mediações que unificam o processo de determinação social da saúde no mundo.

Convém aqui lembrar que utilizamos o termo "unificação" inspirados em Berlinguer ${ }^{11}$, quando argumenta que a corrida marítima do capitalismo, em estágio de formação, na busca por riquezas nas colônias gerou a "unificação microbiana" do mundo. Todavia, acreditamos que o termo "microbiana" se tornou obsoleto no âmbito das Ciências da Saúde, assim como não é suficiente para explicar o status de unidade heterogênea que a saúde global passa a ter, em virtude de se referir às doenças transmissíveis.

Atualmente, há algumas doenças consideradas mundiais, conforme a OMS ${ }^{16}$ demonstra ao observar que $54 \%$ das mortes no mundo se devem a dez causas, a maior parte delas, crônico-degenerativas. Porém, tal qual a antítese espaço-lugar, algumas doenças permanecem como típicas, sejam como endemias sejam com ciclos epidêmicos, em certas regiões do mundo, basta lembrar que o vírus do Ebola tem circulação irrelevante fora do continente africano ou que a malária ainda é típica em países tropicais.

Ademais, lembremos que as mediações unificadoras que citamos não se resumem ao trânsito de pessoas e objetos, mas se referem a todo um estilo de vida, de cultura, filosofia e arte, de organização política etc. que espelham a dinâmica econômica. É evidente, como já mencionamos, que a causalidade própria, por exemplo, do novo coronavírus e o referido trânsito foram, sem dúvida, aspectos relevantes para a efetivação do caráter pandêmico da COVID-19. Contudo, outros elementos que são universais no espaço e no tempo contemporâneo contribuíram decisivamente para tal, sem que precisassem fazer nenhuma viagem, porquanto já sejam universais. Alguns desses elementos vão emergir com as feições contraditórias tipicamente capitalistas, como apontaremos nas reflexões finais.

\section{Algumas reflexões finais (por ora)}

Aqui, visando encerrar a nossa concatenação, apresentamos alguns elementos (mas existem 
outros) que estão presentes no processo de unificação da determinação social da saúde, do qual emerge a pandemia da COVID-19:

1) a prioridade dada à esfera econômica, quando, sobretudo, evita-se obstáculos ao livre comércio, seja nacional seja internacionalmente. Tal condição teve forte influência nas decisões tardias dos governos nacionais em fecharem as fronteiras e adotarem medidas mais rígidas de afastamento social. Embora ainda precisem ser confirmados, há indícios de que o atraso de alguns países europeus em adotar tais medidas contribuiu, sobremodo, à explosão dos casos no continente. É o caso de Espanha, Itália, França, Reino Unido e Alemanha. A título de exemplo, na Itália, após as primeiras mortes serem registradas em fevereiro, alguns prefeitos e governos regionais decretaram quarentena, mas o primeiro-ministro, Giuseppe Conte, conseguiu derrubar tais medidas sob alegação de que elas apenas pregavam o $\operatorname{caos}^{17}$. Pouco tempo depois, a Itália se tornou, por algumas semanas, o epicentro da pandemia e os outros países aqui citados já estavam entre os oito mais afetados.

Todas essas nações foram constrangidas pelas contradições do sistema que defendem, dando um passo atrás e adotando, cedo ou tarde, as medidas de afastamento, ainda que sob tensão contínua por setores das burguesias nacionais e internacionais a fim de adiantar o retorno à normalidade.

2) a fragilização dos sistemas públicos de saúde, fruto, em boa medida, da dinâmica financeira particularizada nos mecanismos das dívidas públicas que implicam sistemas de saúde subfinanciados, em especial com políticas orientadas pelo Banco Mundial ${ }^{18}$. Sistemas de saúde mais sólidos conseguiram sucesso seja na vigilância, caso de alguns países asiáticos como China e Coreia do Sul, seja na redução da mortalidade pela ampla oferta de leitos hospitalares, em especial de terapia intensiva, caso da Alemanha.

A faceta neoliberal do fenômeno de mundialização se depara com as contradições do sistema que sustenta, quando começamos a constatar, até mesmo, discursos de suspensão das dívidas públicas e a defesa de liberação orçamentária emergencial para a saúde. Porém, devemos registrar que um histórico de fragilização dos sistemas públicos de saúde, decerto, implicou menos eficiência no enfrentamento da pandemia a tempo, assim como maior exposição dos seus profissionais de saúde ao adoecimento e morte.

3) A contradição constituída no âmago do neoliberalismo também se reproduz no âmbito da assistência social e previdência, uma vez que países baluartes dessa perspectiva política (que estão no topo da hierarquização da articulação mundial do capitalismo) precisaram injetar boa parte do fundo público em ajudas emergenciais para manter a renda de subsistência de segmentos populacionais e para o combate ao desemprego - por exemplo, o grupo dos 20 países mais ricos (G20) pretende injetar quase 5 trilhões de dólares para enfrentar efeitos sociais do coronavírus $^{19}$. É claro, que a "mão amiga do Estado" não largou a "mão invisível do mercado", porquanto não houve hesitação na implementação de medidas direcionadas ao grande capital, revelando qual seja a real "amizade", a exemplo dos E.U.A., onde a câmara aprovou 2.2 trilhões de dólares para ações econômico-sociais, sendo que 50 bilhões diretamente para grandes empresários e, o restante, indiretamente os beneficiando ${ }^{20}$.

4) $\mathrm{O}$ individualismo burguês é o resultado mais concreto do processo de individuação em face do antagonismo de classe. Em que pese correntes jusnaturalistas defenderem a existência de uma essência humana egoísta, a perspectiva marxiana demonstra como o ser social possui uma dinâmica radicalmente histórica, sendo a forma individualista do indivíduo um produto histórico construído e, portanto, passível de destruição ${ }^{21}$. Com a mundialização do capital, o ethos individualista assume seu apogeu, expressandose na competitividade para além do (mas sempre funcional ao) mercado, como na educação e na cultura ou nas várias narrativas em torno da meritocracia.

Essa forma de "ser" tem profundas relações com as relativizações da gravidade da pandemia e, consequentemente, com a não adesão às medidas preventivas, o que não quer dizer que não haja a coexistência com ações solidárias, de defesa das medidas. Esse ethos individualista converge para a insatisfação pela mudança da rotina cotidiana burguesa e fortalece o argumento de que a economia não pode parar porque é primordial, o que consiste em uma determinação reflexiva com a dinâmica universal do sistema.

5) A intensa disseminação de informações falsas na mídia, em especial via internet, o que costumeiramente se chama de fake news. A nosso ver, a pós-modernidade é um terreno fértil para que a narrativa prevaleça sobre o fato em si, alterando-lhe o contexto. Para Harvey ${ }^{6}$, a condição pós-moderna exprime a compressão espaçotempo peculiar ao capitalismo contemporâneo, quando a efemeridade das formas e do conteúdo na comunicação é uma presença marcante. 
Tal condição é inflada quando a venda de informação atende a interesses econômico-políticos, enquanto signos que contribuem para algum favorecimento na dinâmica capitalista, da produção ao consumo. É claro que esse caráter das comunicações, hoje, contribui para a instantânea reprodução de informações equivocadas sobre a pandemia, gerando incerteza e confusão.

6) Os diferentes impactos que as doenças geram nas classes sociais, sobretudo nos grupos mais pauperizados. De fato, a mundialização do capital gera ainda mais pobreza, e isso é reconhecido pelos autores de diversas perspectivas teóricas. As diferenças de riqueza entre classes ou indivíduos se reflete em indicadores de saúde, revelando maior gravidade, sobretudo, de certas doenças infecciosas ${ }^{22}$. Esse panorama permite refletir sobre a gravidade com a qual a pandemia pode impactar nas comunidades mais pauperizadas, especialmente nos países de capitalismo dependente, devido ao baixo acesso à água tratada, saneamento e estrutura e renda que permita adotar as medidas de prevenção.

Nesse quesito, não se pode deixar de reconhecer que a pandemia, evidentemente, agravará algumas expressões da questão social, especialmente, o desemprego. Inclusive, a narrativa neoliberal oscila entre um discurso a favor das medidas de prevenção (como o afastamento social) e a famigerada defesa da economia, sob o subterfúgio de que a bancarrota (e a miséria que supostamente surge daí) matará mais do que a COVID-19. É necessário analisar essa questão tendo em vista sua dimensão histórico-social, bem como sopesar esse discurso, uma vez que boa parte dos seus porta-vozes são grandes empresários, personificações do grande capital, ou ainda, seus aliados no âmbito político e midiático. Trata-se de uma tergiversação que ignora ou falsifica o fato de que é o capitalismo que, historicamente, gera a desigualdade social e o desemprego, sendo elementos que lhes são estruturais.

Em 2018, existiam 42 milhões de milionários, o que corresponde a $0,8 \%$ da população mundial, mas que acumulavam cerca de 142 trilhões de dólares (44,8\% da riqueza mundial). Ao mesmo tempo, havia 3.211 bilhões de adultos na camada de menor renda, ou $70,1 \%$ da população, que possuíam 6,2 trilhões de dólares, apenas 1,9\% da riqueza total ${ }^{23}$. Já o desemprego é um dos motores dessa desigualdade, sendo que Organização Internacional do Trabalho (OIT) informou que em 2019 a taxa de desemprego global era de 5,4\%, devendo aumentar em 2020. Para a OIT, isso representa uma mudança na tendência de declínio constatada entre 2009 e 2018. Contudo, a mesma instituição apresenta dados que permitem contestar essa tendência, demonstrando que, na verdade, há um deslocamento dos desempregados para o grupo dos subempregados ou desalentados (470 milhões de pessoas em 2019) ${ }^{24}$.

Com efeito, são as medidas econômicas e políticas demandadas pelo enfrentamento da crise estrutural que aumentaram a desigualdade e o desemprego para níveis alarmantes. Portanto, não é a pandemia da COVID-19 a responsável pela da fome e pela miséria, por levar à morte os indivíduos pauperizados da classe trabalhadora, mas o próprio modus operandis do capitalismo, na efetivação diária do seu caráter destrutivo, sobretudo por possibilitar o acúmulo de riqueza nas mãos de poucos e a pauperização daqueles que produzem tal riqueza. A pandemia, então, se constitui enquanto mais um elemento soerguido das bases objetivas do capital mundializado e que adentra nessa espiral contraditória, estabelecendo uma relação de determinação recíproca para com as mesmas, mas estando longe de ser a raiz dos problemas sociais.

Com essas reflexões, encerramos o ensaio, mas o debate apenas se inicia. A nosso ver, são pontos importantes para entender o que se passa, ao menos por ora, quando estamos mergulhados no fato histórico. Post factum poderemos e deveremos recuperar essas e outras questões, a fim de fortalecer um caminho científico e filosófico que rompa com a efemeridade da razão contemporânea. 


\section{Referências}

1. Organização Mundial da Saúde (OMS), Organização Pan-americana da saúde (OPAS). Folha informativa - COVID-19 (doença causada pelo novo coronavírus). $2020 \mathrm{abr}$ [acessado $2020 \mathrm{Abr}$ 17]. [cerca de 10 p.]. Disponível em: https://www.paho.org/bra/index.php?option $=$ com_content\&view $=$ article\&id $=6101$ : covid 19\&Itemid $=875$

2. Andrade CR, Ibiapina CC, Champs NS, Toledo Junior ACC, Picinin IFM. Gripe aviária: a ameaça do século XXI. J bras pneumol 2009; 35(5):470-479.

3. World Health Organization (WHO). Coronavirus disease 2019 (COVID-19). Situation Report. 88. Genebra: WHO; 2020.

4. Chesnais F. Mundialização: o capital financeiro no comando. Revista Outubro 2001; 5:7-28.

5. Fontes V. O Brasil e o capital-imperialismo. Teoria e História. Rio de Janeiro: Ed. UFRJ/Ed. EPSJV; 2010.

6. Harvey D. Condição pós-moderna. Uma pesquisa sobre as origens da mudança cultural. São Paulo: Edições Loyola; 1992.

7. Mészáros I. Para além do Capital: rumo a uma teoria da transição. São Paulo: Boitempo Editorial; 2009.

8. Laurell AC. La salud-enfermedad como proceso social. Revista Latinoamericana de Salud 1982; 2:7-25.

9. Breilh J. La determinación social de la salud como herramienta de transformación hacia una nueva salud pública (salud colectiva). Revista Facultad Nacional de Salud Pública 2013; 31(1):13-27.

10. Fontes V. Capitalismo em tempos de uberização: do emprego ao trabalho. Marx e o Marxismo 2017; 5(8):45-67.

11. Berlinguer G. Globalização e saúde global. Estudos avançados 1999; 13(35):21-38.

12. Lukács G. Para uma ontologia do ser social II. São Paulo: Boitempo; 2013.

13. Souza DO. A saúde na perspectiva da 'Ontologia do ser social'. Trab Educ Saúde 2016; 14(2):337-354.

14. Editorial. Transição demográfica e epidemiológica: a Epidemiologia e Serviços de Saúde revisita e atualiza o tema. Epidemiol Serv Saúde 2012; 21(4):529-532.

15. Fortes PAC, Ribeiro H. Saúde Global em tempos de globalização. Saúde Soc 2014; 23(2):366-375.

16. Organização Mundial da Saúde (OMS), Organização Pan-americana da saúde (OPAS). 10 principais causas de morte no mundo. Folha informativa. $2020 \mathrm{abr}$ [acessado 2020 Abr 19] [cerca de 3 p.]. Disponível em: https://www.paho.org/bra/index.php?option=com content\&view $=$ article\&id $=5638: 10$ - principais-causas-de-morte-no-mundo\&Itemid $=0$
17. Alessi G. Itália pagou preço alto ao resistir a medidas de isolamento social para conter coronavírus. El País [jornal na internet]. 2020 mar [acessado $2020 \mathrm{Abr} 4$ ]. [cerca de 3 p.]. Disponível em: https://brasil.elpais. com/internacional/2020-03-25/italia-pagou-preco-alto-ao-resistir-a-medidas-de-isolamento-social-para-conter-coronavirus.html

18. Souza DO. Financeirização, fundo público e os limites à universalidade da saúde. Saúde debate 2019; 43(spe. 5):71-81.

19. Soares I. G20 injetará US\$ 5 trilhões na economia para combate ao coronavírus. Correio Brasiliense. [acessado 2020 Mar 30]. Disponível em: https:// www.correiobraziliense.com.br/app/noticia/economia/2020/03/26/internas_economia,839185/g20-injetara-us-5-trilhoes-na-economia-para-combate-aocoronavirus.shtml

20. Matsuura S. Trump libera US\$ 50 bilhões para negócios afetados pelo coronavírus nos EUA. O Globo [jornal na internet]. 2020 mar [acessado 2020 Mar 20]. [cerca de 3p.]. Disponível em: https://oglobo.globo. com/economia/trump-libera-us-50-bilhoes-para-negocios-afetados-pelo-coronavirus-nos-eua-24299949

21. Tonet I. Método científico: uma abordagem ontológica. São Paulo: Instituto Lukács; 2013.

22. Buss PM. Globalização, pobreza e saúde. Cien Saude Colet 2007; 12(6):1575-1589.

23. Credit Suisse. Global wealth report 2018. Zurich: Credit Suisse Research Institute; 2018.

24. AFP. Número de desempregados no mundo deve alcançar 190,5 milhões neste ano, diz OIT. G1 [jornal na internet]. 2020 jan [acessado 2020 Abr 10]. [cerca de 2 p.]. Disponível em: https://g1.globo.com/economia/ noticia/2020/01/20/numero-de-desempregados-nomundo-deve-alcancar-1905-milhoes-neste-ano-dizoit.ghtml

Artigo apresentado em 24/04/2020

Aprovado em 26/04/2020

Versão final apresentada em 28/04/2020 
